\title{
Comparison of Child Lunch Meals in Brazil
}

\author{
Carolina Martins $^{1}$, Natália Sanchez Oliveira Jensen ${ }^{2}$, Silvia Maria Franciscato Cozzolino ${ }^{3 *}$ \\ ${ }^{1}$ Bachelor of Science (BSc) in Nutrition from the University of São Paulo, M.D. in Science by the School of Public \\ Health of the University of São Paulo, Equilibrium Consultancy Collaborator, São Paulo, Brazil \\ ${ }^{2}$ Bachelor of Science (BSC) in Nutrition from the University of São Paulo, M.D. in Public Health by the School of \\ Public Health of the University of São Paulo, Nutritional Therapy and Clinical Nutrition Postgraduate Certificate \\ (GANEP), Equilibrium Consultancy Collaborator, São Paulo, Brazil \\ ${ }^{3}$ Department of Food and Experimental Nutrition, Faculty of Pharmaceutical Science, University of São Paulo, \\ São Paulo, Brazil \\ Email: "smfcozzo@usp.br
}

Received 24 March 2016; accepted 22 April 2016; published 25 April 2016

Copyright $(2016$ by authors and Scientific Research Publishing Inc.

This work is licensed under the Creative Commons Attribution International License (CC BY).

http://creativecommons.org/licenses/by/4.0/

(c) (i) Open Access

\begin{abstract}
Background: Recently, revised Dietary Guidelines in Brazil [1] included a recommendation to "avoid fast food". This project compared meals from home and away from home. Objective: To evaluate advertised fast food children's lunch meals and a typical Brazilian homemade meal in relation to recommended intakes for: energy, macronutrients, fiber, sodium, iron and calcium. Methods: Nutritional needs and typical meal intake were estimated, considering $35 \%$ of total daily requirements for a lunch meal. Ranges for energy and macronutrients were calculated, based on varying energy needs by age and activity level. These parameters were compared with nutritional information from company websites and product information collected in São Paulo, Brazil in August, 2014. Results: The majority of children's meals evaluated did not exceed the lunch range for dietary energy and macronutrients. However, $60 \%$ and $50 \%$ of these meals exceeded recommended saturated fat for 4 - 6 and 7 - 10-year-old children, respectively. Most meals fell short for fiber and all meals exceeded sodium recommendations. Micronutrient values were not available for most meals compared. Conclusion: The nutrition quality of lunch in fast food restaurants is similar to a typical Brazilian meal. The restaurant meals could fit into a balanced diet from time to time. Every meal observed here could be improved with regard to sodium and fiber to promote children's health in adulthood.
\end{abstract}

\section{Keywords}

Children, Diet Quality, Fast Food, Dietary Intake, Nutrients

${ }^{*}$ Corresponding author. 


\section{Introduction}

Childhood is a suitable time for nutrition interventions to reduce lifetime risk for noncommunicable disease (NCD) development. Preschool and school age children's diets are commonly low in fruits and vegetables and high in salty snacks, fried goods, sweets, soft drinks and fruit-flavored beverages [2] [3]. According to the Brazilian Survey on School-Age Health (2012), which assessed children's food intake during the previous week, $21.3 \%$ and $19.7 \%$ of school-aged children did not consume fruits and vegetables, respectively. Moreover, $41.3 \%$, $33.2 \%$ and $15.8 \%$ of the respondents ate, respectively, snacks, soft drinks and fried goods on five or more days [4].

Meals away from home are increasingly common and research has tried to assess the impact of this shift on diet quality [5]-[7]. Cimadon et al. (2010) reported 70.3\% of 9 - 18-year-old students from the south of Brazil consuming fast food meals more than four times a week. Here, fast food was defined as breaded foods, burgers, hot dogs, pizza, French fries, fried pastries and packaged soups [8].

Rehm et al. (2014) [9] demonstrated the contribution of fast food restaurants types to the diets of 12,378 US children aged 4 - 19 y using the National Health and Nutrition Examination Survey (NHANES) for the years 2003-2010, and reported that the fast food provided $14.1 \%$ of the energy and $64.8 \%$ of total energy came from store-bought foods and beverages.

There is also a need to assess nutritional quality of homemade meals, since they usually represent the majority of eating occasions for younger children age 5 - 12 years old [10]. Briefel et al. (2009), reported children consumed approximately 530 empty calories during a regular day, including food with high energy density and low nutritional value being eaten at home [11].

There is little research from Brazil evaluating nutritional parameters of children's meals in different eating locations, especially for children under age 10. The present study aimed to assess nutritional quality by considering daily intake recommendations and comparing children's meal bundles from common fast food chains to a typical Brazilian meal, with regard to energy content, as well as macronutrients, fiber, and micronutrients, including sodium, iron and calcium.

\section{Methods}

\subsection{Study Design}

A comparison between: 1) typical homemade Brazilian meal for 4 - 10-year-old children, 2) children’s fast food meal bundles advertised in the restaurants and 3) nutrition recommendations standardized for the 4 - 10-year-old population was performed.

\subsection{Data Source for Estimating Nutrient Intake from a Typical Brazilian Meal}

The values of energy, macro- and micronutrients used in this study for calculating children's typical food intake were based upon those reported by Bueno et al. (2013), with the study coordinator's permission, in a multicenter study with a population $(n=3058)$ of 2 - 6-year-olds from private and public schools in nine Brazilian cities [12]. The daily intake values were calculated by direct individual weighting of food in the schools, together with a food diary recorded by parents or guardians. For this study, data from the 4 - 6-year-old participants were used $(n=1355)$. These intake values were converted into lunch estimated intake, proportional to 35\% of the total intake.

Because no consumption data from a representative population of Brazilian children age 7 - 10 years old were available, the data from Bueno et al. (2013) [12] were extrapolated by calculating the percentage difference between the nutritional recommendation and the food intake of 4 - 6-year-old children for each variable-energy, macro and micronutrients, by physical activity level (PAL). Thus, the respective difference values were applied to the recommendations for the age group 7 - 10, obtaining estimated values.

\subsection{Data Source for Estimating Nutrient Intake from Fast Food Children's Meals}

The fast food child meal bundles were identified based on restaurant advertising or menu features collected in August, 2014 in São Paulo, Brazil at: Bob’s, Burger King, Giraffas, Habib’s and McDonald's. A total of 10 different restaurant meals from five different restaurants were compared: Burger King Club BK with a small size fry, apple slices and apple juice with either a cheeseburger or chicken nugget entrée [13]; Bob’s Tri Kids small size fry, soft drink and either a cheeseburger or chicken nuggets [14]; Giraffas with rice, beans, salad, grape juice and either sliced chicken or beef [15]; Habib’s medium fry, orange juice and either a hot dog or a sfiha 
[16]; and, McDonald's kid size fry, orange juice, and either a cheeseburger and apple slices or chicken nuggets and yogurt [17].

Nutritional information on total energy (kcal), macronutrients, sodium and fiber was obtained through company websites and products labels. When complete nutritional information was not available, these data were collected directly at restaurants or by contacting the customer service departments. Nutritional information of micronutrients, including iron and calcium were also collected, although only McDonald's provided this information.

\subsection{Data Analysis}

The estimated children's dietary intake for both age groups (4 - 6 and 7 - 10 years old) was calculated using nutritional recommendations following the same pattern. For each age group, average weight $(\mathrm{kg})$ and height $(\mathrm{m})$, based on gender, were calculated using anthropometric data from the Brazilian Family Budget Survey (2008-09) [18]. The average values of weight and height were further used to assess the estimated energy requirements (EER), according to the Dietary Reference Intakes (DRI) and gender, including Physical Activity Level (PAL): sedentary, low activity, moderate activity and high activity [19].

Macronutrient recommendations were determined based on the Acceptable Macronutrient Distribution Range (AMDR) with $45 \%$ - 65\% of the total energy intake for carbohydrate, $10 \%-30 \%$ for protein and $25 \%$ - 35\% for fat [19]. The average energy requirement, estimated according to each PAL, was used as a total energy intake reference for calculating the acceptable distribution of macronutrients. For saturated fat, since there is no Institute of Medicine recommendation, the value established by the World Health Organization (WHO) was used [20].

The values for iron (EAR-Estimated Average Requirement), sodium, and fiber (AI-Adequate Intake) followed the DRI [19]-[21]. For the 4 - 6-year-old age group, the recommendations for the 4 - 8-year-olds were used; while for 7 - 10-year-olds, the average value of recommendations for age groups 4 - 8 and 9 - 13 years old was applied. The macronutrient distribution range and values of saturated fat, fiber, sodium and iron for both age groups evaluated in this study (4 - 6 and 7 - 10) were used in assessing the nutrient adequacy of the meals.

Energy values followed the total energy distribution recommendation of $35 \%$ of the daily total, so this proportion was also applied for macro- and micronutrients [22].

\section{Results}

\subsection{Estimated Energy and Nutrient Requirements}

Table 1 shows the estimated energy and nutrient requirements for age groups 4 - 6 and 7 - 10 years, according to PAL. The values, proportional to $35 \%$ of daily requirement, represent the recommended lunch intake.

\subsection{Comparison with Estimated Lunch Requirements}

1) Energy

For total energy at the lunch meal (Figure 1), we estimated a range of 453 - 689 (mean 564) kcal for children age 4 - 6 and 524 - 819 (mean 663) for children age 7 - 10, across all PAL. The estimated home meal for age 7-10 had the highest calories at 690 although this meal was within the range for this age group. The restaurant meals ranged from 419 - $648 \mathrm{kcal}$. Three restaurant meals provided less than 453 calories estimated necessary for a sedentary 4 - 6 year old (both Giraffas meals, McDonald's chicken nugget meal). No meal evaluated exceeded the maximum energy estimated for a highly active 7 - 10-year-old (819 kcal).

2) Macronutrients

For total carbohydrates at the lunch meal (Figure 2), we estimated a range of 64 - 92 (mean 78) g for children age 4 - 6 and 75 - 108 (mean 91) g for children age 7 - 10, across all PAL. Two restaurant meals provided less than $64 \mathrm{~g}$ total carbohydrate estimated necessary for a sedentary 4 - 6 year old (Burger King and McDonald's chicken nugget meals). No meal evaluated exceeded the maximum carbohydrate for a highly active 7 - 10 year old (108 g).

For total protein at the lunch meal (Figure 3), we estimated a range of 14 - 42 (mean 28) g for children age 4 6 and a range of 17 - 50 (mean 33) g for children age 7 - 10, across all PAL. One restaurant meal provided less than $14 \mathrm{~g}$ of protein (Burger King chicken nugget meal-13 g) and all meals observed provided less than the estimated mean for children age $4-6$ of $28 \mathrm{~g}$. 
Table 1. Estimated energy and nutrient requirements for lunch, according to age group and physical activity level.

\begin{tabular}{|c|c|c|c|c|c|c|}
\hline \multirow{2}{*}{$\begin{array}{l}\text { Calories or } \\
\text { Nutrients } \\
\text { Age } 4 \text { - } 6 \text { y old }\end{array}$} & \multicolumn{4}{|c|}{ Physical Activity Level } & \multirow{2}{*}{ Mean (average) } & \multirow{2}{*}{ Range $^{a}$} \\
\hline & Sedentary & Low activity & Moderate activity & High activity & & \\
\hline Energy $(\mathrm{kcal})^{\mathrm{b}}$ & 453 & 523 & 591 & 689 & 564 & $453-689$ \\
\hline Carbohydrate (g) & 62 & 72 & 81 & 95 & 78 & $64-92(45 \%-65 \%)$ \\
\hline Protein $(\mathrm{g})^{\mathrm{b}}$ & 23 & 26 & 30 & 34 & 28 & $14-42(10 \%-30 \%)$ \\
\hline Total fat $(g)^{b}$ & 15 & 17 & 20 & 23 & 19 & $16-22(25 \%-35 \%)$ \\
\hline Saturated fat $(g)^{c}$ & 5 & 6 & 7 & 8 & 6 & $<6(<10 \%)$ \\
\hline Dietary fiber $(\mathrm{g})^{\mathrm{b}}$ & 9 & 9 & 9 & 9 & 9 & \\
\hline Sodium (mg) & 420 & 420 & 420 & 420 & 420 & \\
\hline $\operatorname{Iron}(\mathrm{mg})^{\mathrm{b}}$ & 1.4 & 1.4 & 1.4 & 1.4 & 1.4 & \\
\hline \multirow{2}{*}{$\begin{array}{l}\text { Calories or } \\
\text { Nutrients } \\
\text { Age } 7 \text { - } 10 \text { y old }\end{array}$} & \multicolumn{4}{|c|}{ Physical Activity Level } & \multirow{2}{*}{ Mean (average) } & \multirow{2}{*}{ Range $^{a}$} \\
\hline & Sedentary & Low activity & Moderate activity & High activity & & \\
\hline Energy $(\mathrm{kcal})^{\mathrm{b}}$ & 524 & 612 & 697 & 819 & 663 & $524-819$ \\
\hline Carbohydrate (g) & 72 & 84 & 96 & 113 & 91 & $75-108(45 \%-65 \%)$ \\
\hline Protein $(\mathrm{g})^{\mathrm{b}}$ & 26 & 31 & 35 & 41 & 33 & $17-50(10 \%-30 \%)$ \\
\hline Total fat $(g)^{b}$ & 18 & 20 & 23 & 27 & 22 & $18-26(25 \%-35 \%)$ \\
\hline Saturated fat $(\mathrm{g})^{\mathrm{c}}$ & 6 & 7 & 8 & 9 & 7 & $<7(<10 \%)$ \\
\hline Dietary fiber (g) ${ }^{\mathrm{b}}$ & 10 & 10 & 10 & 10 & 10 & \\
\hline Sodium (mg) & 473 & 473 & 473 & 473 & 473 & \\
\hline Iron (mg) ${ }^{\mathrm{b}}$ & 1.8 & 1.8 & 1.8 & 1.8 & 1.8 & \\
\hline
\end{tabular}

${ }^{\mathrm{a}}$ Dietary Reference Intake (DRI) Acceptable Macronutrient Distribution Range (AMDR). Calculations were performed based on mean energy values across all physical activity levels [19];

${ }^{\mathrm{b}}$ Based on DRI. Calculations were performed based on the estimated energy requirement (EER) for each physical activity level. Values for macronutrients represent the average between minimum and maximum AMDR values [19] [21] [22];

${ }^{\mathrm{c}}$ Based on WHO recommendation [20];

All values presented are proportional to $35 \%$ of daily requirement to represent the recommended lunch intake.

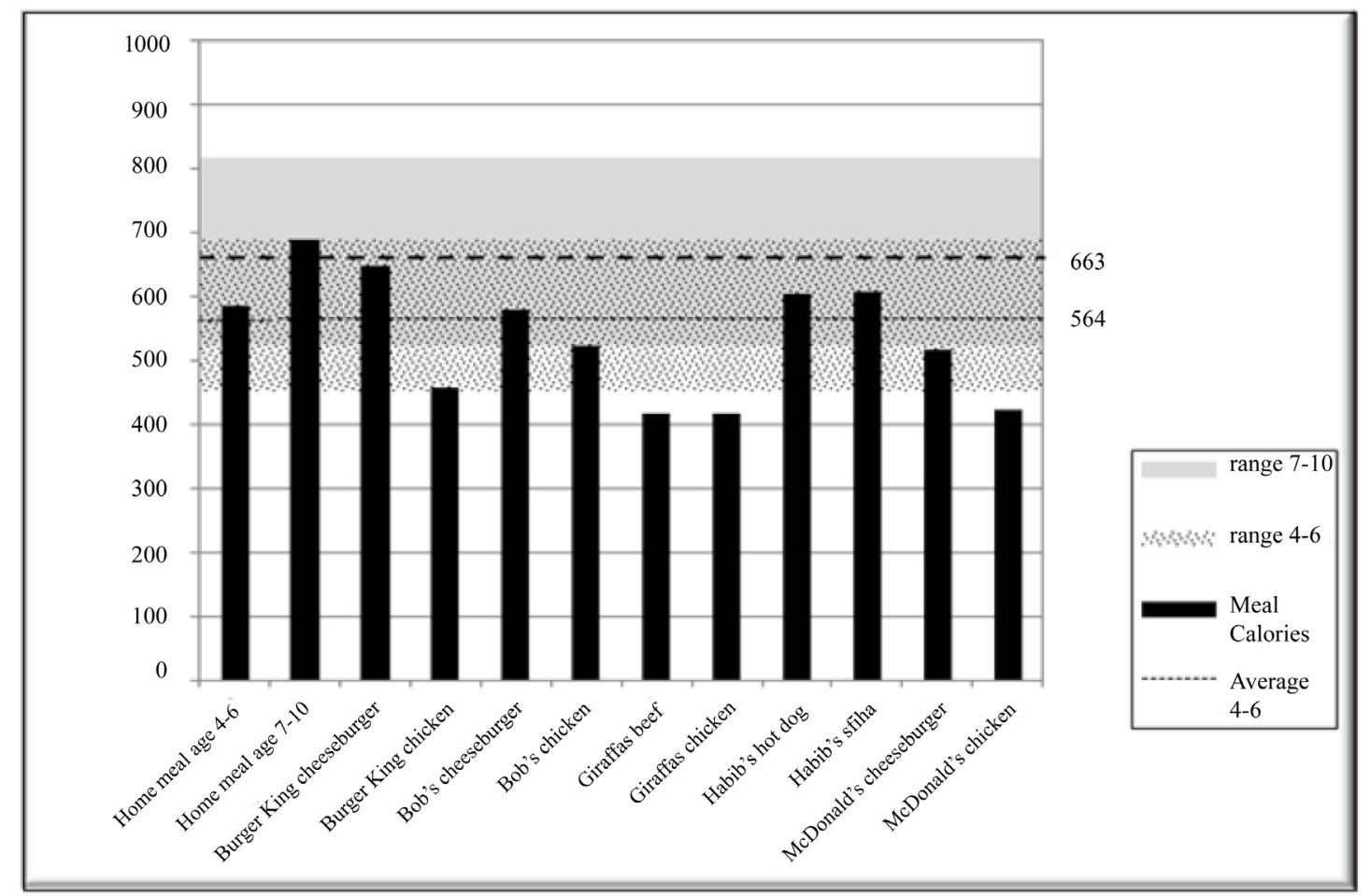

Figure 1. Distribution of lunch calories (kcal) by meal sources, according to the average energy requirement considering the DRI Acceptable Macronutrient Distribution Range (AMDR) recommendation for age groups 4 - 6 and 7 - 10 years old. 


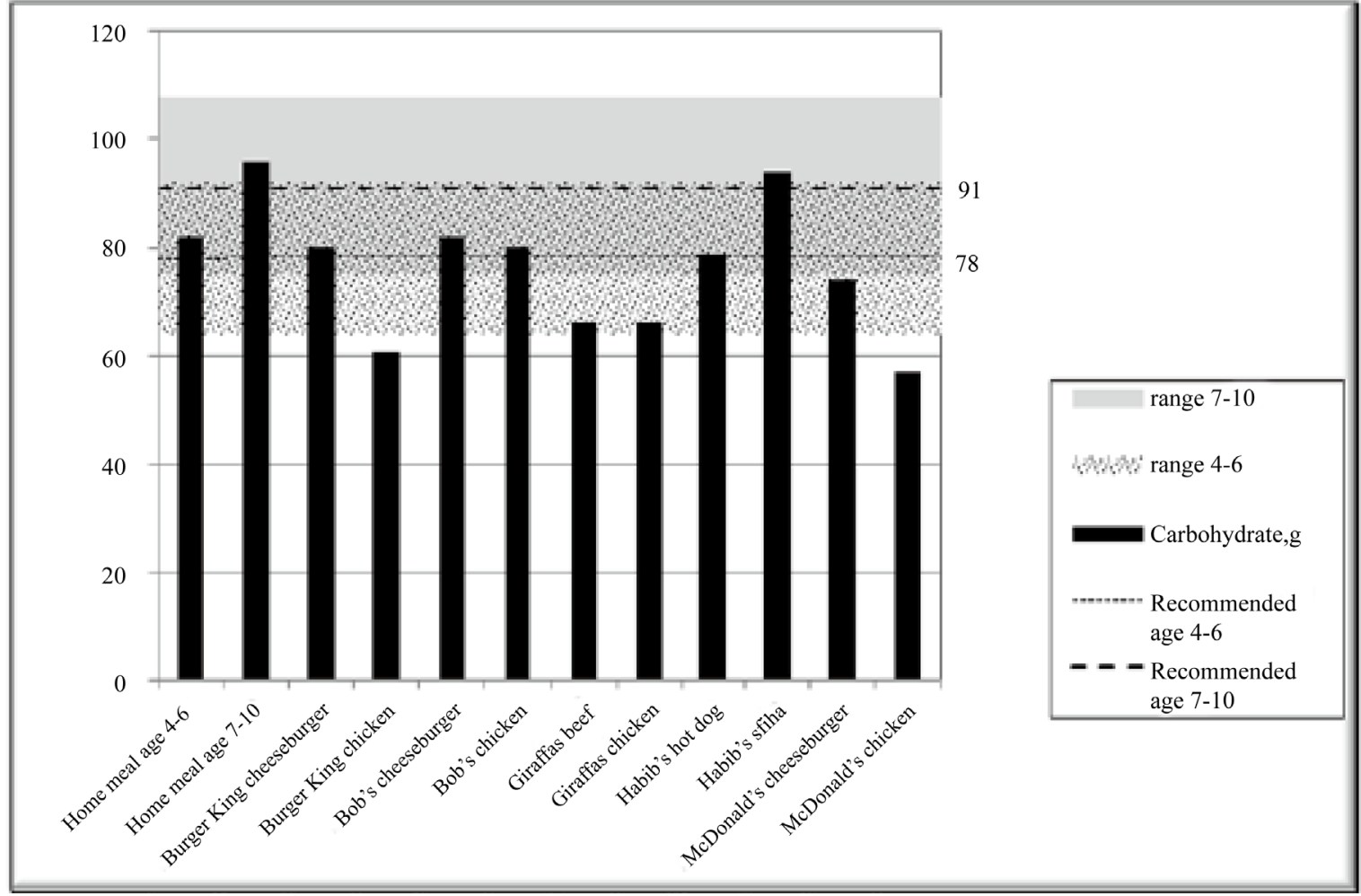

Figure 2. Distribution of lunch carbohydrate (g) by meal sources, according to the average energy requirement considering the DRI Acceptable Macronutrient Distribution Range (AMDR) recommendation for age groups 4 - 6 and 7 - 10 years old.

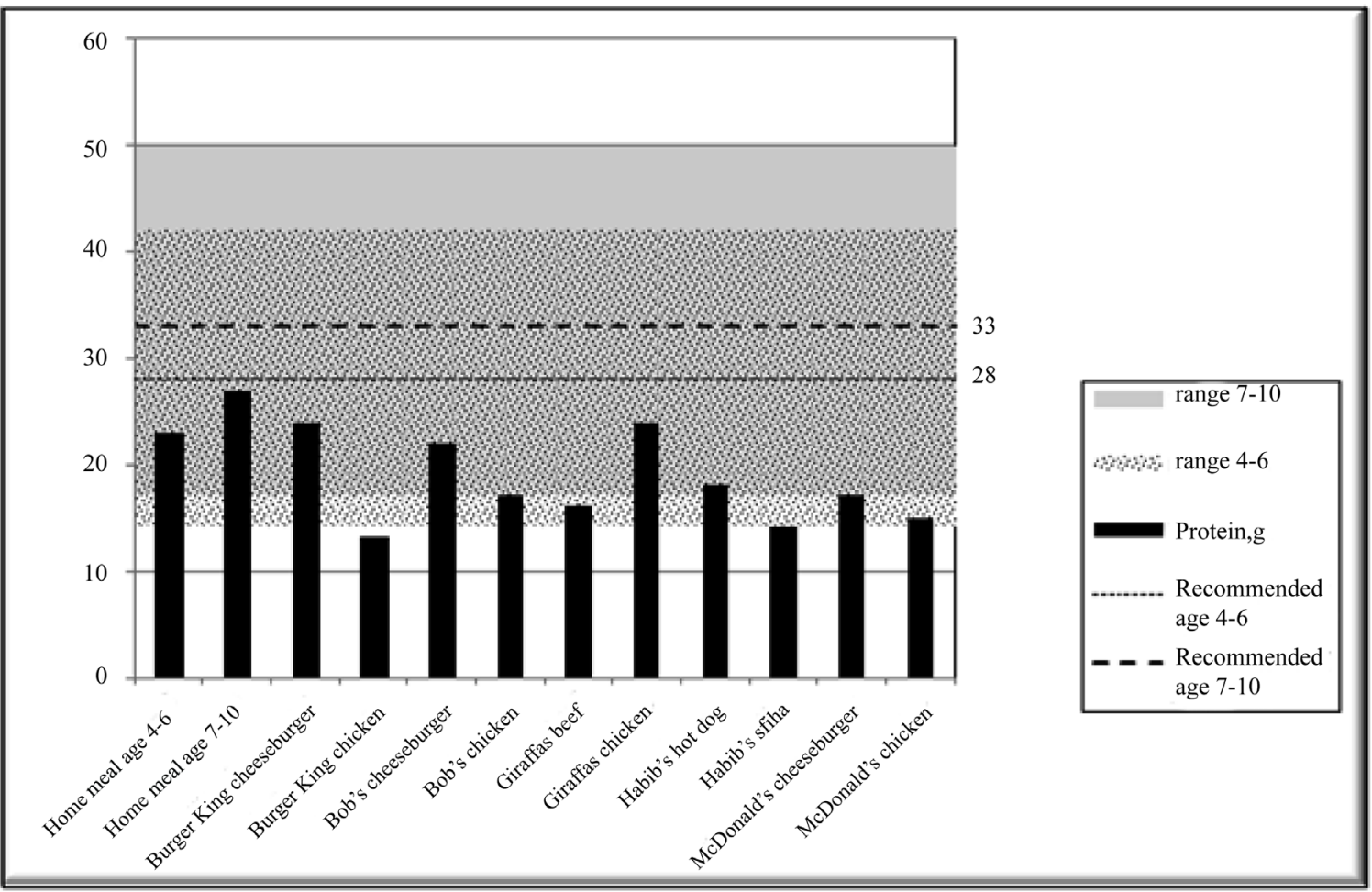

Figure 3. Distribution of lunch protein (g) by meal sources, according to the average energy requirement considering the DRI Acceptable Macronutrient Distribution Range (AMDR) recommendation for age groups 4 - 6 and 7 - 10 years old. 
For fat (Figure 4) and saturated fat (Figure 5), meals lower in total fat were also lower in saturated fat. We estimated the total fat range for a lunch meal at 16 - 22 (mean 19) $\mathrm{g}$ and that saturated fat not exceed $6 \mathrm{~g}$ for children age 4 - 6. For the 7 - 10 age group, we estimated a total fat range of 18 - 26 (mean 22) g and that saturated fat not exceed $7 \mathrm{~g}$. Three meals were below the range for total fat (both Giraffas meals and McDonald's chicken nugget meal). These same meals also had less than $6 \mathrm{~g}$ saturated fat, along with the Burger King chicken nugget meal. Several meals were higher in total fat, but still within the range for older children.

For saturated fat, several meals exceeded $7 \mathrm{~g}$ (home meal for age 7 - 10, Burger King cheeseburger meal, and both meals at Bob's and Habib's). For fiber (Figure 6), we estimated the lunch meal should provide a minimum of $9 \mathrm{~g}$ for children age 4 - 5 and $10 \mathrm{~g}$ for children age 7 - 10. All meals evaluated fell short of this goal except for those at Habib's.

3) Micronutrients

For sodium (Figure 7), we estimated a lunch meal maximum of $420 \mathrm{mg}$ for children age 4 - 6 and $473 \mathrm{mg}$ for children age 7 - 10. Every meal evaluated exceeded both values. The lowest meal was McDonald's chicken nugget at $530 \mathrm{mg}$ and the highest was Burger King's cheeseburger meal at $1093 \mathrm{mg}$.

For iron (data not shown), we estimated lunch should provide $1.4 \mathrm{mg}$ for children age $4-6$ and $1.8 \mathrm{mg}$ for children age 7 - 10. Limited data were available on this micronutrient. The estimated home lunch meals provided $4.6 \mathrm{mg}$ for age 4 - 6 and $5.9 \mathrm{mg}$ for age 7 - 10. McDonald's was the only restaurant providing iron values for their meals, which were $2.8 \mathrm{mg}$ in the chicken nugget meal and $4.4 \mathrm{mg}$ in the cheeseburger meal.

For calcium (data not shown), according to the estimation, lunch should provide $280 \mathrm{mg}$ for children age 4 - 6 and $385 \mathrm{mg}$ for children age 7 - 10. The estimated home lunch meals provided $279.4 \mathrm{mg}$ for age 4 - 6 and 384.2 mg for age 7 - 10. McDonald's was also the only restaurant which provided calcium values for their meals, which were $297 \mathrm{mg}$ in the chicken nugget meal and $151 \mathrm{mg}$ in the cheeseburger meal. Both home lunch and chicken nuggets meals were within the range for younger children.

\subsection{Dessert Options}

The analysis of the restaurant meal menus showed that Burger King included apple slices and McDonald's

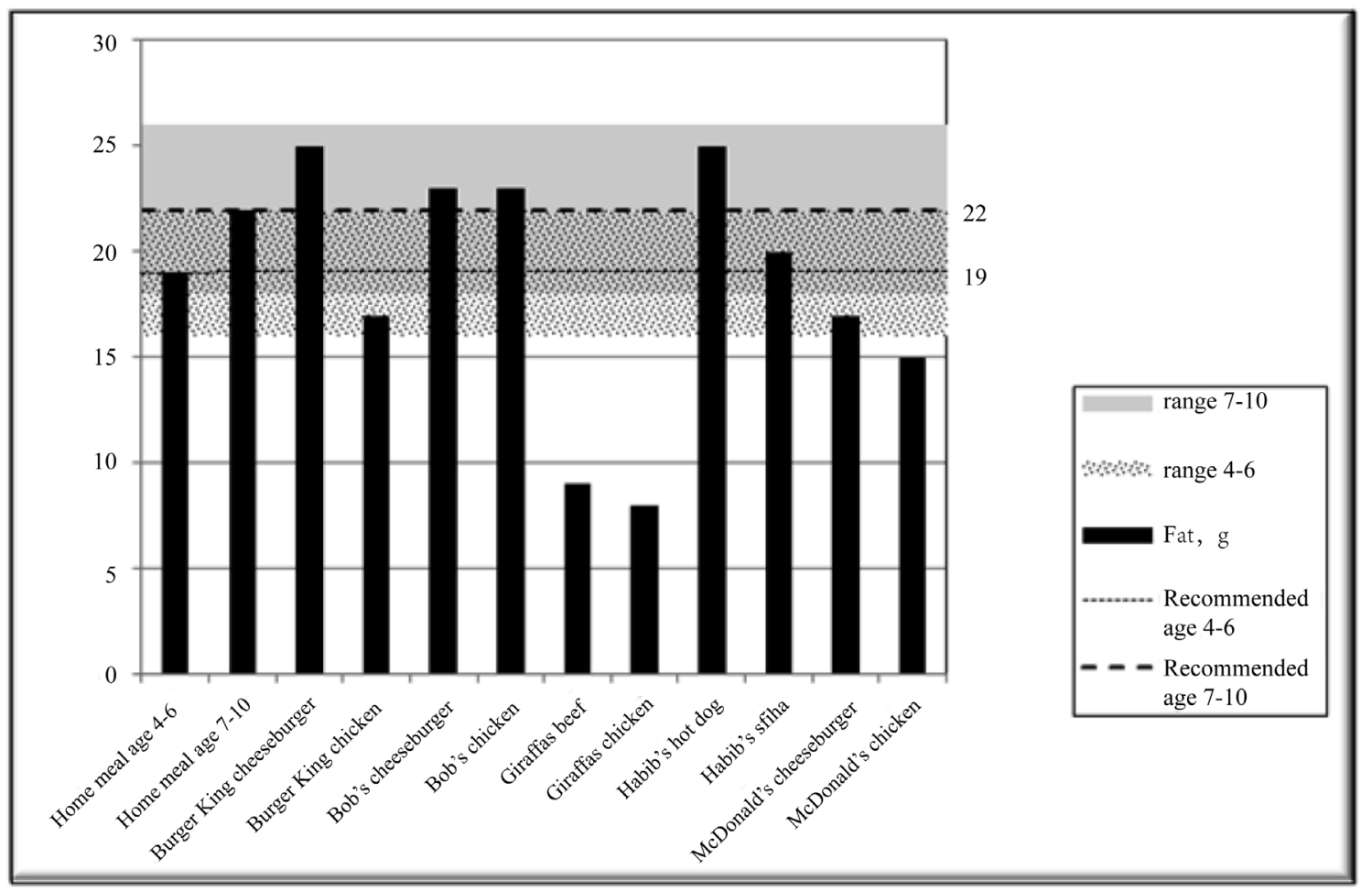

Figure 4. Distribution of lunch total fat (g) by meal sources, according to the average energy requirement considering the DRI Acceptable Macronutrient Distribution Range (AMDR) recommendation for age groups 4 - 6 and 7 - 10 years old. 


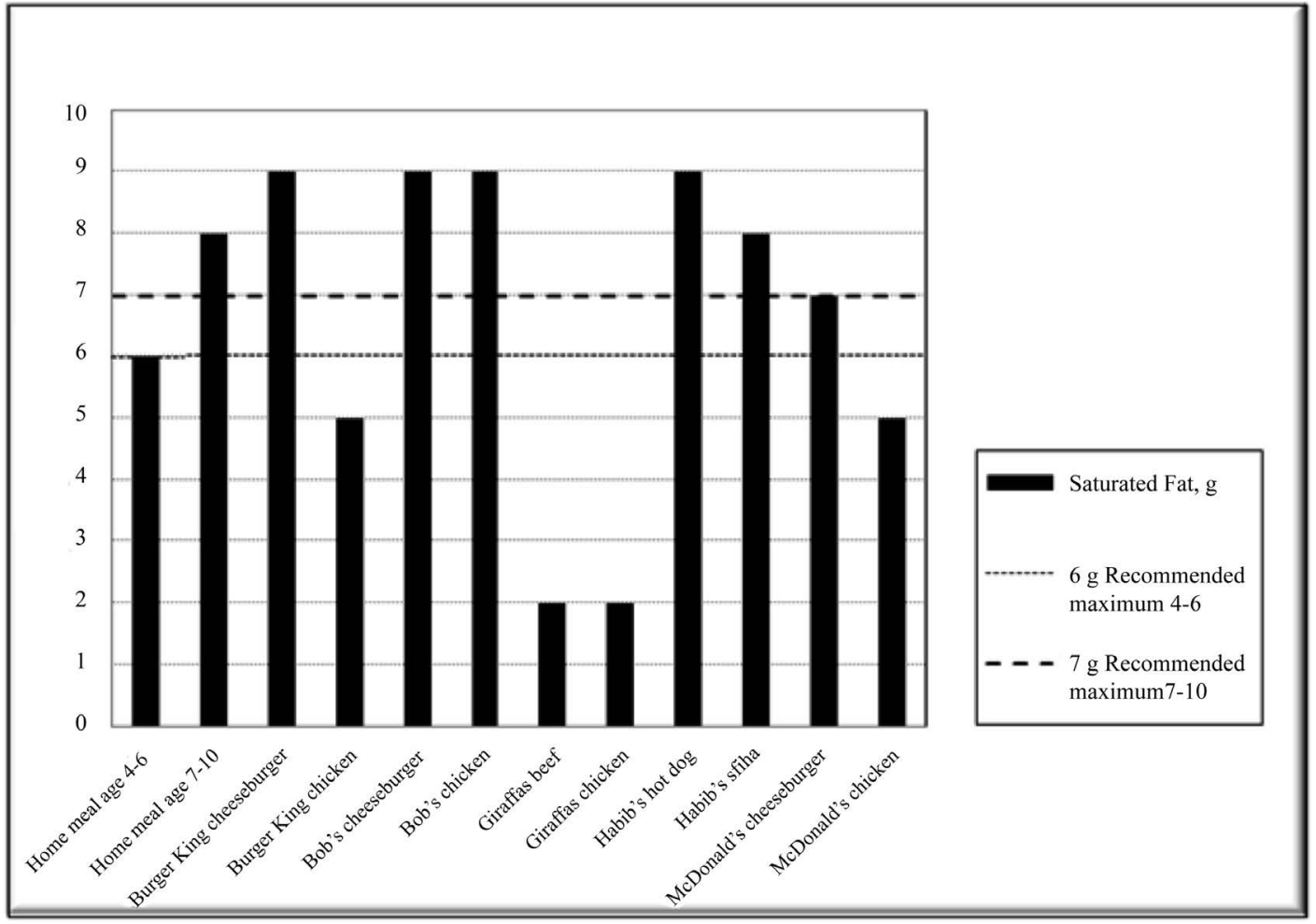

Figure 5. Distribution of lunch saturated fat (g) by meal sources, according to the average energy requirement considering the DRI Acceptable Macronutrient Distribution Range (AMDR) recommendation for age groups 4 - 6 and 7 - 10 years old.

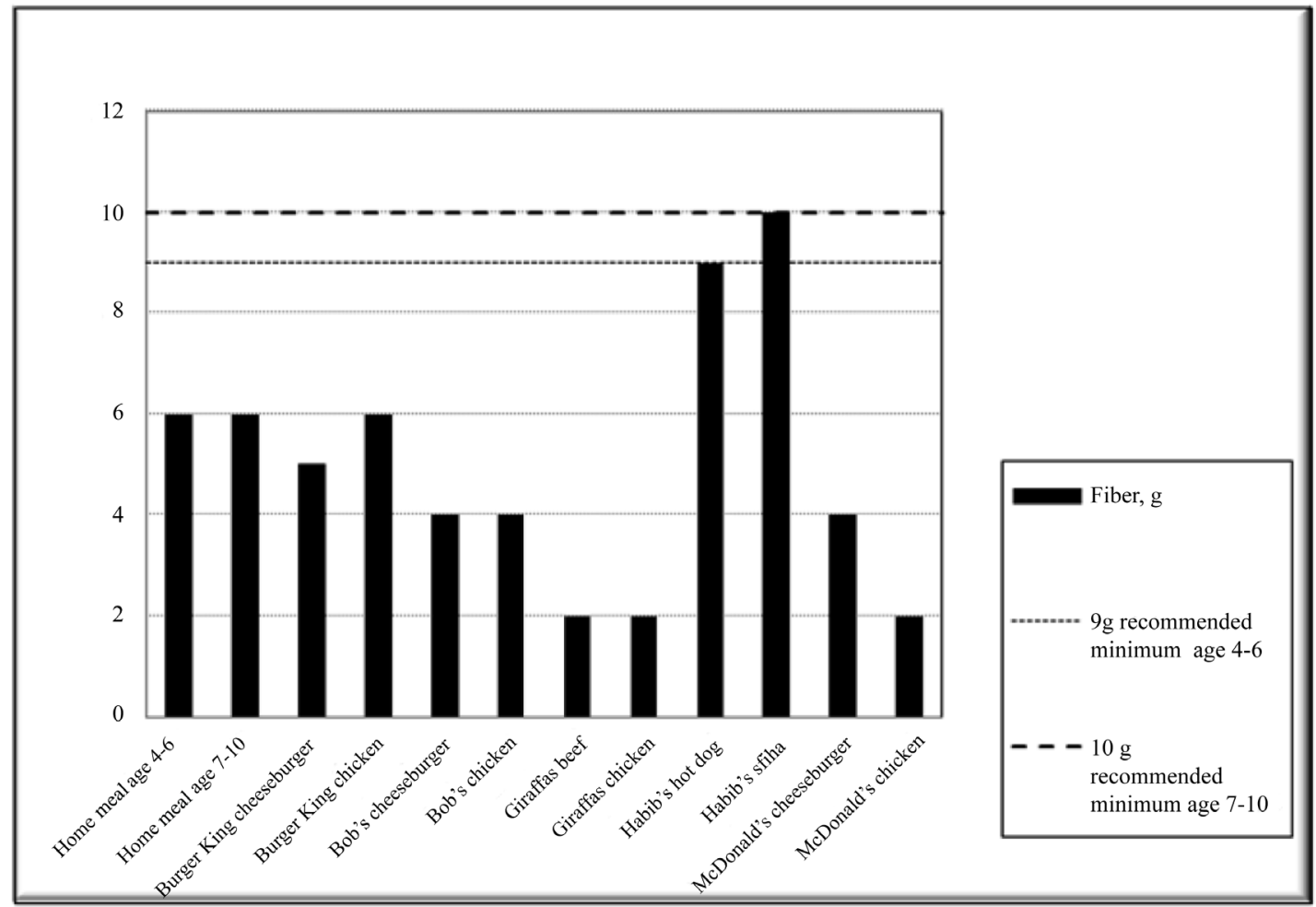

Figure 6. Distribution of lunch fiber (g) by meal sources, according to the average energy requirement considering the DRI Acceptable Macronutrient Distribution Range (AMDR) recommendation for age groups 4 - 6 and 7 - 10 years old. 


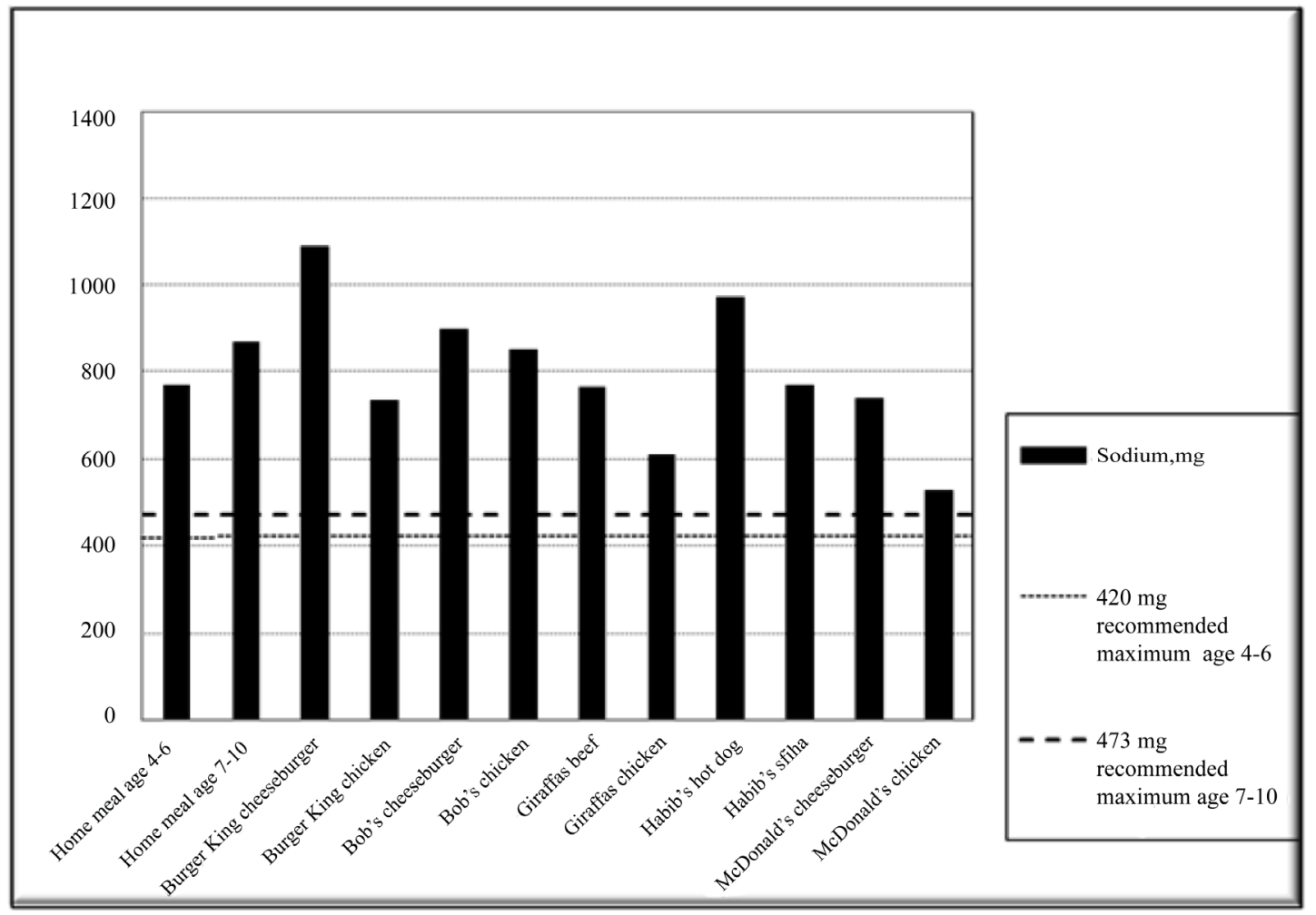

Figure 7. Distribution of lunch sodium (mg) by meal sources, according to the average energy requirement considering the DRI Acceptable Macronutrient Distribution Range (AMDR) recommendation for age groups 4 - 6 and 7 - 10 years old.

included apple slices or yogurt in the meal bundle as a dessert. For the other restaurants no dessert options were included in the meal bundle.

\section{Discussion}

Some researchers suggest that fast food meals are nutritionally inadequate and its regular consumption is associated with excess intake of calories, fat, sodium and sugar, and low fiber intake, factors associated with overweight and obesity in children and teenagers [23] [24].

Assuming an average level of physical activity, all meals analyzed were not excessive in energy content, except for sedentary 4 - 6-year-old children, who need 453 calories at lunch according to our estimates. Three meals did not exceed this value (both from Giraffas and McDonald's chicken). In general, meals including beef or a hot dog had more energy than meals with chicken as the entrée.

Although these findings indicate that child meal bundles offered at common fast-food chains in Brazil may not result in excess energy intake, all lunches compared here, including a typical Brazilian home lunch described by Bueno et al. (2013) [12] provided too much sodium and saturated fat and had insufficient fiber.

Regarding the macronutrients, the total fat value exceeded recommendations for the 4 - 6 year olds in only in two meal bundles (Burger King cheeseburger and Habib's hot dog). For the older children, all the meals did not exceed the recommended range. Three meals were below the recommended range for total fat for all ages - both meals from Giraffas and the McDonald's chicken nugget meal. Meals exceeding both the recommended maximum values for saturated fat by age range ( $6 \mathrm{~g}$ for age $4-6 ; 7 \mathrm{~g}$ for age $7-10$ ), were the homemade meal for age 7 - 10, Burger King cheeseburger meal, both meals from Bob’s, and both meals from Habib's.

We noticed that there might be inconsistency in the values of fiber presented by some fast food chains. For instance, the portion of orange juice (Habib's, hot dog and sfiha options) declares $4.2 \mathrm{~g}$ of fiber, while the portion of rice and salad (Giraffas, chicken/beef option) showed $0 \mathrm{~g}$ of fiber. In both cases, the nutritional information available is not in accordance with the values in food composition tables, so this information may not be reliable. 
Similarly to the fast food meals, the average fiber content $(6 \mathrm{~g})$ in the estimated home meals was also inadequate for both 4 - 6 and 7 - 10-year-olds (9 and 10 g, respectively). This finding is in agreement with other reports of Brazilian school-age children, in which low intake of fruits and vegetables is a common finding [25] [26].

It is important to consider that the reference values for fiber corresponds to the AI, used when EAR cannot be established and, by definition, is higher than the EAR. While EAR is enough to meet the requirements of $50 \%$ of the population, AI aims at the needs of $97 \%$ - 99\% of the healthy population. In agreement with Bueno et al. (2013) [12], it is expected that the population will not be able to attain dietary fiber recommendations given the Brazilian eating habits based on rice, beans and meat.

Regarding sodium content, results pointed out an excess of this nutrient in all the meals evaluated. Others studies have reported an amount of 702 and $956 \mathrm{mg}$ of sodium, respectively, in children's meals from different fast food chains [27] [28].

In the USA, findings from NHANES 2003-2008 showed that $61.4 \%$ of daily sodium for 6 - 11 year-old children came from food purchased at stores, $13.3 \%$ from fast food or pizza chains, $10.4 \%$ from school foods, $5.8 \%$ from full service restaurants, and the rest from other locations [29].

In the USA the majority of sodium comes from ready-to-eat food, while in Brazil $74.4 \%$ of comes from the addition of salt and salt-based seasonings added to food at home [30]. Because the Bueno et al. (2013) data used here to estimate typical home lunches were based on standardized recipes, it is possible this amount is underestimated [12]. Preference for salty foods is a dietary habit in Brazil requiring public health education programs.

With regard to iron, only one restaurant chain provided this information. The meals were adequate $(1.8 \mathrm{mg}$ and $4.4 \mathrm{mg}$ ), as were the homemade meals. Despite the low prevalence of inadequate iron intake, dietary sources and varying bioavailability should be considered. Iron bioavailability is usually low, ranging from $5 \%$ to $12 \%$ in a typical Brazilian diet and reaching higher proportions (14\% - 18\%) when foods rich in heme iron (meats) are included in the diet. The recommendation for this mineral assumes that $75 \%$ of the total intake is obtained from heme iron sources [21].

Although the iron intake of Brazilian children from their typical meals may be higher than from fast food meals, the main iron sources in the Brazilian diet are rice and beans, which are sources of non-heme iron [31]. Hence, the meals with meat are good sources of bioavailable iron.

Rice et al. (2007) affirms that meals consumed at fast food outlets can be included in a well-planned, healthy diet [32]. Moreover, many companies have improved their menus. In a study that evaluated the nutritional quality of North American fast food chains between 1997/98 and 2009/10 using the Healthy Eating Index, it was demonstrated that the amount of saturated fat and the proportion of calories coming from solid fat and added sugar in fast food meals has decreased over time [33].

We observed that just a few of fast food children's menus offer fruit as a dessert option, which would be a useful strategy to increase fiber content. At the same time, an increased presence of fruits and vegetables in children's meals probably needs to overcome the acceptance barrier, since the low intake seems more correlated to taste issues than to their availability [34]. For example, Befort et al. (2006) found the availability of fruits and vegetables at home reported by parents was not associated to their consumption by teenagers [35].

Consumer availability of nutritional information can have a positive effect on the food choices parents make for their kids. In a study carried out in the USA, the impact of the total energy information disclosed on McDonald's menus was investigated. The intervention group received a menu showing the calorie content, while the control group received the menu without calories. The parents' orders from the intervention group presented a significantly lower energy value than the control, with an average reduction of 102 calories [36].

A law in the state of São Paulo, Brazil (Law n. 14677) requires that all foods sold in fast food chains must provide nutritional information on calories, macronutrients, and sodium to consumers, with all information displayed on individual packages and, whenever possible, in posters, brochures and nutritional tables visible to the public [37].

The reduction in portion size can also be an intervention target [38]. Wansink \& Hanks (2014) evaluated the effect of reducing by 56\% the portion size of French fries, as implemented by McDonald's in North and South America in 2012, on possible within-meal calorie compensation by the main dish and beverage selection. The results showed no calorie compensation, since the comparison between orders before and after the change showed a reduction of $19 \%$ in total child meal calories, demonstrating the feasibility of such strategy. The authors suggest parents can reduce portion size at home in the same way [39]. 


\section{Conclusion}

The nutrition quality of lunch in fast food restaurants is similar to a typical Brazilian meal. The restaurant meals could fit into a healthy diet from time to time. Every meal observed here could be improved with regard to sodium and fiber to promote children's health in adulthood. Accurate and more comprehensive nutrition information, including the important minerals iron and calcium, should be encouraged on packaged or restaurant foods. These comparisons illustrate that focus should be placed on nutritional quality rather than on eating place. It is important to have education programs for families and schools to illustrate the role of adequate nutrition in childhood and chronic disease prevention.

\section{Acknowledgements}

The authors acknowledge Equilibrium Consultancy which led this study. Funding by McDonald's Corporation for the project was primarily to Equilibrium. The contributions of the authors were as follows-Martins C had full access to the data in the study; Martins C, Jensen NSO, Cozzolino SMF: study concept and design; Martins C: acquisition of data; Martins C, Jensen NSO: interpretation of data, drafting of the manuscript; Martins C, Jensen NSO, Cozzolino SMF; critical revisions. Competing Interests: MC and JNSO have no conflicts to report. CSMF advises McDonald's on nutrition issues.

\section{References}

[1] Brasil. Ministério da Saúde (2014) Secretaria de Atenção à Saúde. Departamento de Atenção Básica. Guia alimentar para a população brasileira. 2nd Edition, Ministério da Saúde, Brasília.

[2] Neutzling, M.B., Araújo, C.L., Vieira, M.F.A., et al. (2010) Intake of Fat and Fiber-Rich Foods According to Socioeconomic Status: The 11-Year Follow-Up of the 1993 Pelotas (Brazil) Birth Cohort Study. Cadernos de Saúde Pública, 26, 1904-1911. http://dx.doi.org/10.1590/S0102-311X2010001000006

[3] Alves, M.N., Muniz, L.C. and Vieira, M.F.A. (2013) Food Intake among Brazilian Children Aged Two to Five Years Old: National Survey on Demography and Health (NSDH), 2006. Ciência \& Saúde Coletiva, 18, 3369-3377. http://dx.doi.org/10.1590/S1413-81232013001100026

[4] Instituto Brasileiro de Geografia e Estatística—IBGE (2013) Diretoria de Pesquisas. Coordenação de População e Indicadores Sociais. Pesquisa Nacional de Saúde do Escolar-2012. IBGE, Rio de Janeiro.

[5] Instituto Brasileiro de Geografia e Estatística-IBGE (2010) Diretoria de Pesquisas, Coordenação de Trabalho e Rendimento, Pesquisa de Orçamentos Familiares 2008-2009. Despesas, rendimentos e condições de vida. IBGE, Rio de Janeiro.

[6] Bezerra, I.N. and Sichieri, R. (2010) Characteristics and Spending on Out-of-Home Eating in Brazil. Revista de Saúde Pública, 44, 221-229.

[7] Gorgulho, B.M., Fisberg, R.M. and Marchioni, D.M. (2013) Nutritional Quality of Major Meals Consumed Away from Home in Brazil and Its Association with the Overall Diet Quality. Preventive Medicine, 57, 98-101. http://dx.doi.org/10.1016/j.ypmed.2013.04.020

[8] Cimadon, H.M.S., Geremia, R. and Pellanda, L.C. (2010) Dietary Habits and Risk Factors for Atherosclerosis in Students from Bento Gonçalves (state of Rio Grande do Sul). Arquivos Brasileiros de Cardiologia, 95, 166-172. http://dx.doi.org/10.1590/S0066-782X2010005000088

[9] Rehm, C.D. and Drewnowski, A. (2014) A New Method to Monitor the Contribution of Fast Food Restaurants to the Diets of US Children. PLOS ONE, 9, e103543. http://dx.doi.org/10.1371/journal.pone.0103543

[10] Burke, S.J., McCarthy, S.N., O’Neill, J.L., et al. (2007) An Examination of the Influence of Eating Location on the Diets of Irish Children. Public Health Nutrition, 10, 599-607. http://dx.doi.org/10.1017/S1368980007258379

[11] Briefel, R.R., Wilson, A. and Gleason, P.M. (2009) Consumption of Low-Nutrient, Energy-Dense Foods and Beverages at School, Home, and Other Locations among School Lunch Participants and Nonparticipants. Journal of the American Dietetic Association, 109, S79-S90. http://dx.doi.org/10.1016/j.jada.2008.10.064

[12] Bueno, M.B., Fisberg, R.M., Maximino, P., de Pádua Rodrigues, G. and Fisberg, M. (2013) Nutritional Risk among Brazilian Children 2 to 6 Years Old: A Multicenter study. Nutrition, 29, 405-410. http://dx.doi.org/10.1016/j.nut.2012.06.012

[13] Burger King. http://burgerking.s3-website-us-east1.amazonaws.com/sites/default/TabelaNutricional BK 08abril.PDF

[14] Bob’s. http://www.bobs.com.br/cardapio

[15] GIRAFFAS Brazil. http://www.giraffas.com.br/download/tabela_nutricional_2014_2.pdf

[16] Habib’s. http://www.habibs.com.br/_pdf/tabela_Nutricional_Habibs.pdf 
[17] McDonald’s Brazil. http://www.mcdonalds.com.br/

[18] Instituto Brasileiro de Geografia e Estatística-IBGE (2010) Diretoria de Pesquisas, Coordenação de Trabalho e Rendimento, Pesquisa de Orçamentos Familiares 2008-2009. Antropometria e estado nutricional de crianças, adolescentes e adultos no Brasil. IBGE, Rio de Janeiro.

[19] Institute of Medicine (2005) Dietary Reference Intakes for Energy, Carbohydrate, Fiber, Fat, Fatty Acids, Cholesterol, Protein, and Amino Acids (Macronutrients). The National Academies Press, Washington DC.

[20] World Health Organization (2003) Diet Nutrition and the Prevention of Chronic Diseases: Report of a Joint WHO/ FAO Expert Consultation. WHO Technical Report Series 916, World Health Organization, Geneva.

[21] Institute of Medicine (2001) Dietary Reference Intakes for Vitamin A, Vitamin K, Arsenic, Boron, Chromium, Copper, Iodine, Iron, Manganese, Molybdenum, Nickel, Silicon, Vanadium, and Zinc. National Academy of Sciences, National Academy Press, Washington DC.

[22] Institute of Medicine (2004) Dietary Reference Intakes for Water, Potassium, Sodium, Chloride, and Sulfate. National Academy Press, Washington DC.

[23] Philippi, S.T. (2008) Pirâmide dos Alimentos: Fundamentos Básicos da Nutrição. Manole, Barueri, SP.

[24] Bowman, S.A., Gortmaker, S.L., Ebbeling, C.B., Pereira, M.A. and Ludwig, D.S. (2004) Effects of Fast-Food Consumption on Energy Intake and Diet Quality among Children in a National Household Survey. Pediatrics, 113, 112- 118.

[25] Powell, L.M. and Nguyen, B.T. (2013) Fast-Food and Full-Service Restaurant Consumption among Children and Adolescents: Effect on Energy, Beverage, and Nutrient Intake. JAMA Pediatrics, 167, 14-20. http://dx.doi.org/10.1001/jamapediatrics.2013.417

[26] Assis, M.A., Calvo, M.C., Kupek, E., et al. (2010) Qualitative Analysis of the Diet of a Probabilistic Sample of Schoolchildren from Florianópolis, Santa Catarina State, Brazil, Using the Previous Day Food Questionnaire. Cadernos de Saúde Pública, 26, 1355-1365. http://dx.doi.org/10.1590/S0102-311X2010000700014

[27] De Carvalho, A.P., de Oliveira, V.B. and do Santos, L.C. (2010) Hábitos Alimentares e Práticas de Educação Nutricional: Atenção a Crianças de Uma Escola Municipal de Belo Horizonte, Minas Gerais. Pediatria (São Paulo), 32, 20-27.

[28] Wellard, L., Glasson, C. and Chapman, K. (2012) Fries or a Fruit Bag? Investigating the Nutritional Composition of Fast Food Children's Meals. Appetite, 58, 105-110. http://dx.doi.org/10.1016/j.appet.2011.09.024

[29] Wu, H.W. and Sturm, R. (2013) What's on the Menu? A Review of the Energy and Nutritional Content of US Chain Restaurant Menus. Public Health Nutrition, 16, 87-96. http://dx.doi.org/10.1017/S136898001200122X

[30] Drewnowski, A. and Rehm, C.D. (2013) Sodium Intakes of US Children and Adults from Foods and Beverages by Location of Origin and by Specific Food Source. Nutrients, 5, 1840-1855. http://dx.doi.org/10.3390/nu5061840

[31] Instituto Brasileiro de Geografia e Estatística (2011) Pesquisa de Orçamentos Familiares 2008-2009. Análise do Consumo Alimentar Pessoal no Brasil. IBGE, Rio de Janeiro.

[32] Rice, S., McAllister, E.J. and Dhurandhar, N.V. (2007) Fast Food: Friendly? International Journal of Obesity, 31, 884886. http://dx.doi.org/10.1038/sj.ijo.0803580

[33] Hearst, M.O., Harnack, L.J., Bauer, K.W., Earnest, A.A., French, S.A. and Oakes, J.M. (2013) Nutritional Quality at Eight U.S. Fast-Food Chains-14-Year Trends. American Journal of Preventive Medicine, 44, 589-594. http://dx.doi.org/10.1016/j.amepre.2013.01.028

[34] Paeratakul, S., Ferdinand, D.P., Champagne, C.M., Ryan, D.H. and Bray, G.A. (2003) Fast-Food Consumption among US Adults and Children: Dietary and Nutrient Intake Profile. Journal of the American Dietetic Association, 103, 13321338. http://dx.doi.org/10.1016/S0002-8223(03)01086-1

[35] Befort, C., Kaur, H., Nollen, N., et al. (2006) Fruit, Vegetable, and Fat Intake among Non-Hispanic Black and NonHispanic White Adolescents: Associations with Home Availability and Food Consumption Settings. Journal of the American Dietetic Association, 106, 367-373. http://dx.doi.org/10.1016/j.jada.2005.12.001

[36] Tandon, P.S., Wright, J., Zhou, C., Rogers, C.B. and Christakis, D.A. (2010) Nutrition Menu Labeling may Lead to Lower-Calorie Restaurant Meal Choices for Children. Pediatrics, 125, 244-248. http://dx.doi.org/10.1542/peds.2009-1117

[37] Assembleia Legislativa do Estado de São Paulo. Lei No 14.677, de 29 de Dezembro de 2011. Obriga as Redes de "Fast Food” a Informar aos Consumidores o Valor Nutricional dos Alimentos Comercializados. http://www.al.sp.gov.br/repositorio/legislacao/lei/2011/lei-14677-29.12.2011.html

[38] Serrano, E.L. and Jedda, V.B. (2009) Comparison of Fast-Food and Non-Fast-Food Children's Menu Items. Journal of Nutrition Education and Behavior, 41, 132-137. http://dx.doi.org/10.1016/j.jneb.2008.02.005

[39] Wansink, B. and Hanks, A.S. (2014) Calorie Reductions and Within-Meal Calorie Compensation in Children’s Meal Combos. Obesity (Silver Spring), 22, 630-632. http://dx.doi.org/10.1002/oby.20668 